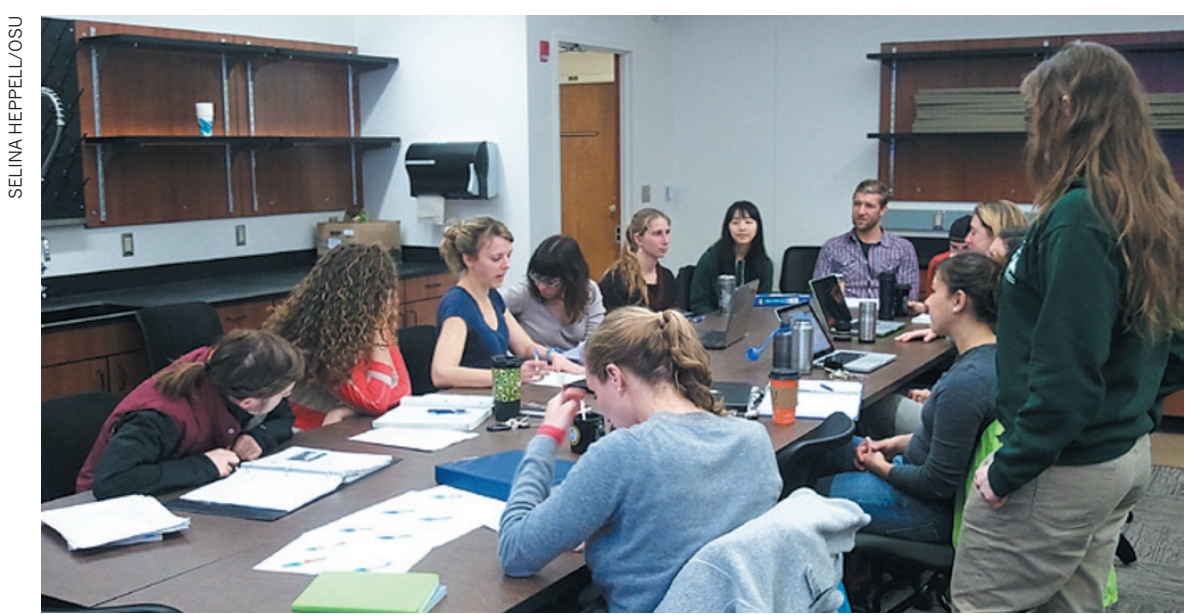

A seminar team at Oregon State University works through the trials of collaboration.

groups have struggled because of funding, travel or infrastructure difficulties at home. However, the team at the Federal University of Rio Grande do Sul in Porto Alegre, Brazil, has thrived: taking advantage of their strong backgrounds in statistics and mathematics, its students have published a paper.

Graduate student Vanessa Weinberger, a team leader at the Pontifical Catholic University of Chile in Santiago, says that she has benefited from working with a large team of people who do not share her background in theoretical ecology, and from the opportunity to present research in English. In Chile, she says, it is relatively unusual for graduate students from different laboratories - let alone different universities - to collaborate on a project outside their theses.

\section{BRANCHING OUT}

The DBDGS is set to end this year, but George Gilchrist, an NSF programme director, says that its good results have prompted the foundation to consider repeating the exercise. The NCEAS would also be open to hosting further distributed seminars, says deputy director Stephanie Hampton. The centre is currently hosting its first three-week institute for earlycareer researchers, which had more than 400 applicants from around the world. The 22 successful participants, including several graduate students, are learning skills for collaborative, data-intensive ecological research. The programme runs from 19 June to 10 July, and the NCEAS plans to offer it each year.

With a colleague, Helene Wagner, a landscape ecologist at the University of Toronto Mississauga in Canada, has led two landscape-genetics courses based on the distributed-seminar model. Students could opt to participate in group projects using existing data sets and simulation studies. The first, conducted in person and online in 2010, resulted in five papers. Unlike the mostly single-institution DBDGS groups, each team was made up of a mix of students from the 15 participating universities in North
America and Europe, including the Swiss Federal Institute of Technology in Zurich and Joseph Fourier University in Grenoble, France. The second course took place entirely online, mitigating student travel expenses; even students who were not at a participating institution could sign up. A similar course is planned for 2014.

In the United Kingdom, Vitae, a Cambridge-based organization that focuses on researchers' professional development, has offered publishing workshops with Macmillan Science Communication in London (which has the same parent company as Nature). It also runs a course called The Collaborative Researcher, which brings together 40 researchers at a time to learn skills including communication, cultural awareness, planning and negotiation.

\section{SIDE PROJECTS}

Seminars such as these take up precious time, which is often in short supply for graduate students. Dee extols the skills and collaborations that she has gained from the DBDGS - but says that the process took longer than anyone expected. She estimates that it delayed her thesis by four months. But her $\mathrm{CV}$, she hopes, will boast papers from both the seminar and her cross-seminar collaborations - and some of the work that she is doing with OSU students will be part of her dissertation.

Heppell told students in her team - particularly those who signed up to tackle big workloads, such as data analysis - that they needed to have a serious talk with their advisers about how much time it would take. She has not heard any complaints; in fact, advisers have commented that if students get publications, the DBDGS is a good use of their time. "I think advisers realize that the stakes are higher now," she says, referring to research funding challenges. "The jobs are fewer." -

Cameron Walker is a freelance writer based in Santa Barbara, California.

\section{COLLABORATION}

\section{US and UK join forces}

The United States and Britain are launching a global research collaboration to address issues such as water supply and climate change in emerging nations. The 5 -year programme will fund up to a total of 40 US and UK grants per year, says Richard Everitt, deputy director of the British Council USA in Washington DC. He did not disclose amounts but said that awards could last for up to three years. Funding will come from the British Council, the UK Department for Business, Innovation and Skills and the US Department of State. "We want to create a cadre of young researchers who can work with their counterparts from the emerging world," says Everitt. The initiative will form partnerships with universities in nations such as China, Brazil, India and Indonesia, and will seek grant proposals in September.

\section{RESEARCH IMPACT}

\section{Bang not based on buck}

Grant size does not strongly predict scientific impact, according to a study published in PLOS ONE. The authors used four measures - publications, citations, highly cited papers and citations of the most-highly cited paper - to score the impact of 374 researchers funded between 2002 and 2006 by the Natural Sciences and Engineering Research Council of Canada. Grant sizes explained less than 30\% of the variation (J.-M. Fortin and D. J. Currie PLOS ONE 8, e65263; 2013). Co-author David Currie, a biologist at the University of Ottawa, says, "Some very poorly funded people manage to do a great deal."

\section{UNITED KINGDOM}

\section{Funding freeze critiqued}

A UK science-advocacy group says that a repeated freeze to the government's $£ 4$-6-billion (US\$7-billion) scienceresearch budget, announced on 26 June, will damage early-career researchers' work and drive them to other nations. Science is Vital, formed to track the results of a 2010 budget freeze, polled 868 UK researchers, and found that $70 \%$ of junior scientists have lost confidence in research careers in Britain. Some $59 \%$ of respondents applying for grants said their success rate had fallen; $39 \%$ of those with labs have recruited fewer PhD students and 19\% could not recruit any. "Frustrated young researchers are leaving," says Jennifer Rohn, chair of Science is Vital and a cell biologist at University College London. 